University of Nebraska - Lincoln

DigitalCommons@University of Nebraska - Lincoln

January 1995

\title{
Genetic and Phenotypic (Co)Variances for Growth and Carcass Traits of Purebred and Composite Populations of Beef Cattle
}

\author{
K. E. Gregory \\ L. V. Cundiff \\ R. M. Koch
}

Follow this and additional works at: https://digitalcommons.unl.edu/usdaarsfacpub

Part of the Agricultural Science Commons

Gregory, K. E.; Cundiff, L. V.; and Koch, R. M., "Genetic and Phenotypic (Co)Variances for Growth and Carcass Traits of Purebred and Composite Populations of Beef Cattle" (1995). Publications from USDAARS / UNL Faculty. 158.

https://digitalcommons.unl.edu/usdaarsfacpub/158

This Article is brought to you for free and open access by the U.S. Department of Agriculture: Agricultural Research Service, Lincoln, Nebraska at DigitalCommons@University of Nebraska - Lincoln. It has been accepted for inclusion in Publications from USDA-ARS / UNL Faculty by an authorized administrator of DigitalCommons@University of Nebraska - Lincoln. 


\title{
Genetic and Phenotypic (Co)Variances for Growth and Carcass Traits of Purebred and Composite Populations of Beef Cattle ${ }^{1,2}$
}

\author{
K. E. Gregorys', L. V. Cundiff, and R. M. Koch ${ }^{4}$ \\ Roman L. Hruska U.S. Meat Animal Research Center, ARS, USDA, Clay Center, NE 68933
}

\begin{abstract}
Least squares means, genetic $\left(\sigma_{\mathrm{g}}\right)$, and phenotypic ( $\sigma_{\mathrm{p}}$ ) standard deviations, and phenotypic coefficients of variation ( $\mathrm{CV}$ ) were estimated on an age-constant basis for growth, carcass, and meat traits of castrate males from 12 breed groups combined, for 9 purebreds combined, and for the $F_{3}$ generation of three composite populations combined to which the nine purebreds contributed. Also, heritabilities $\left(h^{2}\right)$ and genetic $\left(r_{g}\right)$ and phenotypic $\left(r_{p}\right)$ correlations were estimated among growth, carcass, and meat traits for all breed groups combined involving 1,594 individuals that were the progeny of 306 sires (214 purebred and 92 composites). Coefficients of variation and $\sigma_{\mathrm{g}}$ generally were similar for composites and contributing purebreds for growth and size-related traits. For traits relating to carcass
\end{abstract}

composition and meat quality, means, $\sigma_{\mathrm{p}}$, or $\mathrm{CV}$ for composites and contributing purebreds generally were similar. Generally, estimates of $\sigma_{\mathrm{g}}$ and $\mathrm{h}^{2}$ were similar among all breed groups combined, contributing purebreds combined, and composites combined. Generally, $r_{g}$ were high among all measures of carcass fat, indicating major difficulty in achieving a high percentage of retail product simultaneously with a high fat content of the longissimus muscle that is required for carcass quality grade. Generally, $r_{p}$ were of smaller magnitude than $r_{g}$. All $r_{p}$ of marbling score or percentage of ether-extracted fat in the longissimus muscle with all end-use properties relating to palatability including shear force, and sensory evaluation of tenderness, juiciness, and flavor were below 30 .

Key Words: Cattle, Growth, Carcass, Heritabilities, Genetic Correlation, Phenotypic Correlation

\section{Introduction}

Heritability estimates of, and genetic and phenotypic correlations among, growth, carcass, and meat traits in genetically diverse populations of cattle were reported by Koch et al. (1982). The paper by Koch et al. (1982) reviewed rather variable estimates of heritability for some growth and carcass traits that had been reported in eight different studies. Comparison of composite populations with their contributing purebreds for genetic and phenotypic variation for growth, carcass, and meat traits has not been reported. Gregory et al. (1994a,b) suggested compos-

\footnotetext{
${ }^{1}$ Published as paper no. 10918, Journal Ser., Nebraska Agric. Res. Div., Univ. of Nebraska, Lincoln 68583-0908.

${ }^{2}$ Appreciation is expressed to Gordon Hays, Wade Smith, Robert Bennett, Dave Powell, Patricia Beska, Dave Kohmetscher, Kay Theer, Jeff Waechter, and their staff for operations support provided to this project; to Darrell Light for data analyses; to Deborah Brown for secretarial support; and to Michael Dikeman for assistance on carcass evaluation

${ }^{3}$ To whom correspondence should be addressed.

${ }^{4}$ Animal Sci. Dept., Univ. of Nebraska, Lincoln 68583-0908.

Received April 8, 1994.

Accepted March 16, 1995
}

ite breeds as an effective procedure to use breed differences to achieve and maintain an optimum balance of carcass composition and beef quality attributes for each of a wide range of production and marketing situations. The objective of this study was to estimate genetic and phenotypic variances and heritabilities of, and genetic and phenotypic correlations among, growth, carcass, and meat traits of composite and contributing purebred populations of cattle.

\section{Materials and Methods}

Experimental Animals. There were 1,594 animals by 306 sires from 12 breed groups included in this study. Number of animals and sires, respectively, by breed group were Red Poll [R] 114, 21; Braunvieh [B] 137, 26; Hereford [H] 132, 22; Angus [A] 117, 23; Simmental [S] 126, 19; Limousin [L] 138, 24; Charolais [C] 124, 25; Gelbvieh [G] 147, 27; Pinzgauer [P] 118, 27; and three composite populations to which the nine purebreds contributed, MARC I: $(157,38), 1 / 4 \mathrm{~B}, 1 / 4 \mathrm{~L}$, $1 / 4 \mathrm{C}, 1 / 8 \mathrm{H}, 1 / 8 \mathrm{~A}$; MARC II: $(146,30), 1 / 4 \mathrm{~S}, 1 / 4 \mathrm{G}, 1 / 4 \mathrm{H}$, $1 / 4 \mathrm{~A}$; and MARC III: $(138,24) 1 / 4 \mathrm{R}, 1 / 4 \mathrm{P}, 1 / 4 \mathrm{H}, 1 / 4 \mathrm{~A}$. 
Composites were from the $F_{3}$ generation resulting from inter se mating of $\mathrm{F}_{2}$ generation sires and dams of the same breed composition (Gregory et al., 1994a). All animals included in this study were born in 1988, 1989,1990 , and 1991 from dams that were $2,3,4$, or $\geq$ 5 yr old.

Feeding and Management. Mean birth date of animals included in this experiment was April 13. In the last $3 \mathrm{yr}$ animals were weaned at an average age of approximately $150 \mathrm{~d}$ on September 7 or 11 . Because of drought in 1988, animals were weaned on August 18 at an average age of $127 \mathrm{~d}$. Weight at $200 \mathrm{~d}$ was estimated using $A D G$ from birth to weaning plus birth weight. Following weaning, animals were started on a diet of $2.65 \mathrm{Mcal}$ of $\mathrm{ME} / \mathrm{kg}$ of dry matter and $15.4 \%$ crude protein composed of ground alfalfa hay, corn, corn silage, and protein-mineral supplement. Corn silage replaced ground alfalfa hay and corn on a gradual basis to a backgrounding diet that was 2.69 Mcal of ME $/ \mathrm{kg}$ of dry matter and $12.88 \%$ crude protein composed of corn silage $(66 \%)$, corn $(22 \%)$, and protein-mineral supplement (12\%). At an average age of $203 \mathrm{~d}$ between October 30 and November 15 over the $4 \mathrm{yr}$, animals of each breed group were weighed and were assigned to treatment on a random basis stratified by weight. Before assigning animals to treatment, seven to nine males in each breed group were identified as candidate replacement sires. Candidate replacement sires were identified to represent a broad pedigree base and were near the mean weight of their respective breed group.

Treatment was dietary energy density with two finishing diets for each year-breed-group subclass. Feed level 1 (finishing diet) was $2.83 \mathrm{Mcal}$ of $\mathrm{ME} / \mathrm{kg}$ of dry matter and $11.50 \%$ crude protein. Feed level 2 (finishing diet) was $3.07 \mathrm{Mcal}$ of $\mathrm{ME} / \mathrm{kg}$ of dry matter and $11.50 \%$ crude protein. Composition of diet (dry matter basis) for feed level 1 was corn silage $(59.77 \%)$, rolled corn $(32.77 \%)$, and protein-mineral supplement $(7.46 \%$ ). Composition of diet (dry matter basis) for feed level 2 was corn silage $(18.00 \%)$, rolled corn $(75.24 \%)$, and protein-mineral supplement $(6.76 \%)$.

Animals were kept on the backgrounding diet (2.69 Mcal of ME $/ \mathrm{kg}$ of dry matter and $12.88 \% \mathrm{CP}$ ) for different periods in different years before changing to the finishing diet. Dietary change dates by birth year were as follows: 1988, February 27; 1989, January 31; 1990, January 2; and 1991, November 11. Animals had ad libitum access to feed. Fresh feed was provided two times each day.

Immediately after assignment to treatment, animals were castrated. Animals born in 1988 and 1989 were castrated by standard surgical procedures, whereas animals born in 1990 and 1991 were castrated by a banding procedure that prevented circulation of blood to the testes.

Slaughter and Processing Procedures. Animals were serially slaughtered at four end points with 20,21 , or
$22 \mathrm{~d}$ between slaughter dates and $63 \mathrm{~d}$ between first and fourth slaughter. Initial slaughter date was between May 21 and 26 for the 4 yr. Days between initial weight $(203 \mathrm{~d})$ to final weight averaged 204 , 224,245 , and $267 \mathrm{~d}$ for the four slaughter groups. Thus, mean days fed from initial to final weight was 235 and mean slaughter age was $438 \mathrm{~d}$. Steers were assigned to slaughter group on a random basis stratified by weight based on the last weight taken before the start of the serial slaughter schedule. Final weight taken 7 or $8 \mathrm{~d}$ before slaughter was a single weight taken starting at 0700 , after overnight access to feed and water. All steers remaining in the experiment were weighed before each slaughter date. Weights of animals slaughtered at the first three slaughter dates averaged approximately the same as animals remaining in a pen.

Animals were slaughtered in a commercial facility. Following a chill period of $24 \mathrm{~h}$, fat thickness at the 12 th rib, fat thickness at 12th rib adjusted for differences in distribution of subcutaneous fat for the entire carcass, estimated perirenal fat percentage, and longissimus muscle area were obtained and the right side of each carcass was returned to the U.S. Meat Animal Research Center to obtain carcass cut-out, chemical composition, and meat sensory data. For animals born in 1988, 1989, and 1990, limitations on carcass processing capability forced random sampling of sides for detailed cut-out and meat sensory data. This included a total of 65 carcasses on which cut-out and sensory data were not obtained in the $3 \mathrm{yr}$.

Carcasses were processed into wholesale cuts of round, loin, rib, chuck, plate, flank, and brisket plus shank. Each wholesale cut was fabricated into boneless steaks, roasts, lean trim, and fat trim to $8 \mathrm{~mm}$ of fat trim except that the dorsal and lateral vertebral processes in the short loin and dorsal vertebral processes and ribs were left in standing rib roasts. Lean trim was targeted to contain $20 \%$ chemical fat. Further processing removed all subcutaneous and accessible intermuscular fat ( $0 \mathrm{~mm}$ of fat cover) from any surface and the remaining bone was removed from the short loin and from the standing rib roasts. The 9-10-11th rib cut was removed and processed by the procedure described for wholesale cuts and kept separate from the remainder of the rib. Soft tissue (lean and fat) from the 9-10-11th rib cut was ground and sampled to determine water and fat.

Retail product included trimmed ( 8 or $0 \mathrm{~mm}$ of fat cover) steaks and roasts plus lean trim adjusted to $20 \%$ fat based on chemical analysis of the lean trim. Lean trim was ground and sampled for water and fat determinations to provide a basis for adjusting retail product to $80 \%$ lean and $20 \%$ fat in the lean trim.

Three longissimus muscle steaks, cut $2.54 \mathrm{~cm}$ thick from the 5-6th and 12th ribs, were frozen on $d 9$ after slaughter and were used for chemical determination of water and fat in the longissimus muscle, for WarnerBratzler shear force, and trained sensory panel evaluation of the longissimus muscle. Water was 
determined by oven drying and fat was determined by ether extraction. Procedures for thawing, cooking, coring, and serving samples to the trained sensory panel and for shearing cores followed AMSA (1978) guidelines, except that steaks for shear force determination were chilled overnight.

Analysis of Data. Data were analyzed by least squares mixed model procedures (Harvey, 1985). The fixed effects included in the model were breed group (nine parental breeds in the model for purebreds, three composite populations in the model for composite populations, and nine parental breeds plus three composites in the model for combined analyses); feed level, slaughter group, year of birth, age of dam $(2,3$, $4, \geq 5 \mathrm{yr}$ ), and the regressions of each trait on date of birth and the interaction of breed group $x$ date of birth. Thus, postweaning growth and carcass and meat data are adjusted to a constant age of $438 \mathrm{~d}$. Interactions among main effects were not important $(P>.05)$. Sire within breed group was included in each model as a random effect for each analysis. In a separate analysis, carcass weight and breed group $x$ carcass weight were included in the model that included all breed groups as covariates. Estimates of variance components among sires $\left(\sigma_{\mathbf{s}}^{2}\right)$ and residual $\left(\boldsymbol{\sigma}_{\mathbf{e}}^{\mathbf{2}}\right)$ were used to estimate genetic $\left(\sigma_{\mathrm{g}}\right)$ and phenotypic $\left(\sigma_{\mathbf{p}}\right)$ standard deviations. Genetic standard deviations were estimated by $\sqrt{4 \times \sigma_{\mathrm{s}}^{2}}$. Phenotypic standard deviations were estimated by $\sqrt{\sigma_{\mathrm{s}}^{2}+\sigma_{\mathrm{e}}^{2}}$. Heritability $\left(\mathrm{h}^{2}\right)$ was estimated by $4 \sigma_{\mathrm{s}}^{2} /\left(\sigma_{\mathrm{s}}^{2}+\sigma_{\mathrm{e}}^{2}\right)$. Coefficients of variation ( $\mathrm{CV}$ ) were computed $\mathrm{CV}=\sigma_{\mathrm{p}}$ / $\overline{\mathbf{x}}$. Genetic and phenotypic correlations were calculated by $\operatorname{COV}_{\mathrm{si} \text { sj }} /\left(\sigma_{\mathrm{si}} \times \sigma_{\mathrm{sj}}\right)$ and $\operatorname{COV} \mathrm{P}_{\mathrm{i}} \mathrm{P}_{\mathrm{j}} /\left(\sigma \mathrm{P}_{\mathrm{i}} \times \sigma \mathrm{P}_{\mathrm{j}}\right)$, respectively, where si and si refer to genetic value of traits $i$ and $j$ and where $P_{i}$ and $P_{j}$ refer to phenotypic value of traits $i$ and $j$.

In each analysis the component breed groups are assumed to have a common variance. The estimates of genetic (co)variances reflect average values for breed groups included in each of the three primary analyses.

The sire model provided for by the LSMLMW program (Harvey, 1985) was chosen over alternative models and programs (e.g., DFREML, Boldman et al., 1993 ) because it was important to estimate covariances among a large number of traits in the analyses. Computing efficiency greatly favored the use of the sire model over alternative models. Also, the advantages of using MTDFREML were thought to be relatively small because the parental purebred and composite populations were unselected and matings had provided for a low rate of inbreeding.

\section{Results and Discussion}

The number of sires and individuals, respectively, for all breed groups, purebreds, and composites were $306,1,594 ; 214,1,153$; and $92,441$.
Least Squares Means, Genetic, and Phenotypic Standard Deviations, and Phenotypic Coefficients of Variation. Least squares means $(\overline{\mathrm{x}}), \sigma_{\mathrm{g}}, \sigma_{\mathrm{p}}$, and phenotypic $\mathrm{CV}$ for 1) all breed groups, 2) purebreds, and 3) composites are presented in Table 1. Because of retained heterosis, composites had heavier mean weights than contributing purebreds and tended to have proportionately higher $\sigma_{\mathrm{p}}$ for traits associated with heavier weight. Coefficients of variation were similar in composites and contributing purebreds for carcass traits associated with weight, and for carcass composition.

For the difference between composite and contributing purebred variance components $\left(\sigma_{g}^{2}\right)$ to be significant $(P<.05)$ the variance must be 1.34 -fold larger for one than for the other ( $F$-test, Snedecor and Cochran, 1967). For the 26 traits reported in this study (Table 1), six traits did not differ in $\sigma_{\mathrm{g}}^{2}(P>$ $.05)$, for seven traits $\sigma_{\mathrm{g}}^{2}$ was greater $(P<.05)$ in the contributing purebreds, and for 13 traits $\sigma_{\mathrm{g}}^{2}$ was greater $(P<.05)$ in the composites.

For traits relating to carcass composition, composites had a higher percentage of fat in the carcass than contributing purebreds, consistent with previous reports on effects of heterosis on carcass composition (e.g., Gregory et al., 1994a,b). After adjusting carcass composition for differences in weight, composites and contributing purebreds did not differ in carcass composition. Least squares means for composites and contributing purebreds generally were similar for traits relating to carcass composition and meat quality. For traits associated with carcass and meat quality, composites and contributing purebreds were similar in both $\sigma_{\mathrm{p}}$ and in CV. There were no consistent differences between composites and contributing purebreds in $\sigma_{\mathrm{g}}$.

Heritabilities. Heritabilities $\left(\mathrm{h}^{2}\right)$ and their approximate standard errors for all breed groups combined, contributing purebreds, and for composites are presented in Table 2. Considering the magnitude of the standard errors, estimates of heritability for the traits evaluated were remarkably similar for composites and for contributing purebreds. There was not a consistent tendency for $\mathrm{h}^{2}$ for the composites to be greater than for the contributing purebreds.

Heritabilities for all breed groups combined for growth traits are of similar magnitude for all phases of growth. Heritabilities of traits reflecting carcass composition are similar to growth traits. Heritability of marbling score and percentage of longissimus muscle fat were of the same magnitude and were higher than for growth traits. Heritability of traits relating to meat palatability generally were low. Muscling score in the live animal, a subjective evaluation, had highest $h^{2}$ among the traits analyzed (.64). The low heritability of shear force (.12) 


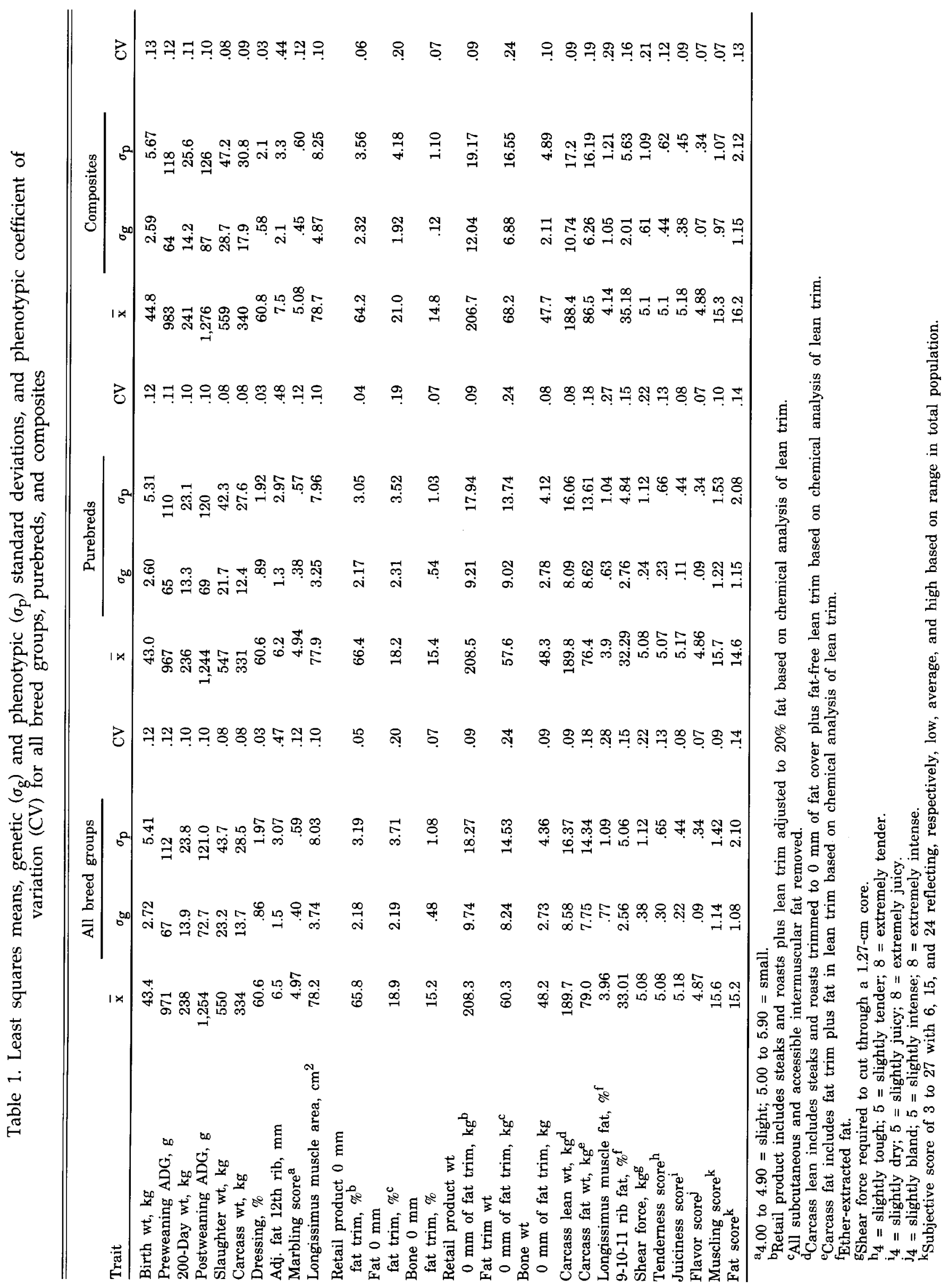


suggests that differences in shear force were likely evaluated with higher error variance. These estimates of $\mathrm{h}^{2}$ tend to be slightly lower for the same or similar traits than those reported by Koch et al. (1982); shear force was considerably lower (.31 vs .12). Also, these estimates of $h^{2}$ tend to be toward the lower end of the range for similar traits reported in a review paper by Koots et al. (1994).

Genetic Correlations. Estimates of $r_{g}$ and their approximate standard errors for all breed groups combined are presented below the diagonal in Table 3 for traits of primary interest. The $r_{g}$ of slaughter and carcass weight with the components of carcass weight (e.g., carcass bone, carcass lean, and carcass fat weight) were high. The $r_{g}$ of adjusted fat at 12 th rib, marbling score, and longissimus muscle fat with carcass composition (e.g., percentage of retail product and carcass fat weight) were high. However, the $\mathbf{r}_{\mathrm{g}}$ of marbling score with other measures of fat were lower than those reported by Cundiff et al. (1964) and by Koch et al. (1982). The positive $r_{g}$ of marbling score with other measures of fat (e.g., .66 \pm .12 with percentage of fat trim) and negative $r_{g}$ between marbling score and measures of carcass composition (e.g., $-.60 \pm .20$ with percentage of retail product) reflect the difficulty of genetically increasing marbling score while maintaining a favorable lean:fat ratio in the carcass. The $\mathbf{r}_{\mathrm{g}}$ of marbling score with percentage

Table 2. Heritabilities $\left(\mathrm{h}^{2}\right)$ and approximate standard errors (SE) for all breed groups, purebreds, and composites

\begin{tabular}{|c|c|c|c|c|c|c|}
\hline \multirow[b]{2}{*}{ Trait } & \multicolumn{2}{|c|}{ All breed groups } & \multicolumn{2}{|c|}{ Purebreds } & \multicolumn{2}{|c|}{ Composites } \\
\hline & $\mathrm{h}^{2}$ & SE & $\mathrm{h}^{2}$ & SE & $\mathrm{h}^{2}$ & SE \\
\hline Birth wt & .25 & .08 & .24 & .10 & .26 & .17 \\
\hline Preweaning ADG & .35 & .09 & .35 & .10 & .30 & .17 \\
\hline 200-Day wt & .34 & .09 & .33 & .10 & .31 & .17 \\
\hline Postweaning ADG & .36 & .09 & .33 & .10 & .48 & .18 \\
\hline Slaughter wt & .28 & .08 & .26 & .10 & .37 & .18 \\
\hline Carcass wt & .23 & .08 & .20 & .10 & .34 & .17 \\
\hline Dressing percentage & .19 & .08 & .22 & .10 & .08 & .15 \\
\hline Adj. fat 12 th rib & .25 & .08 & .20 & .10 & .39 & .18 \\
\hline Marbling score ${ }^{\mathrm{a}}$ & .48 & .09 & .45 & .11 & .55 & .19 \\
\hline Longissimus muscle area & .22 & .08 & .17 & .09 & .35 & .18 \\
\hline $\begin{array}{l}\text { Retail product } 0 \mathrm{~mm} \\
\text { fat trim, } \%^{\mathrm{b}}\end{array}$ & .47 & .09 & .51 & .11 & .42 & .18 \\
\hline $\begin{array}{l}\text { Fat } 0 \mathrm{~mm} \\
\text { fat trim, } \% \mathrm{c}\end{array}$ & .35 & .09 & .43 & .11 & .21 & .16 \\
\hline $\begin{array}{l}\text { Bone } 0 \mathrm{~mm} \\
\text { fat trim, } \%\end{array}$ & .21 & .08 & .27 & .10 & .01 & .15 \\
\hline $\begin{array}{l}\text { Retail product wt } \\
\mathbf{0} \mathrm{mm} \text { of fat trim }\end{array}$ & .28 & .08 & .26 & .10 & .39 & .18 \\
\hline $\begin{array}{l}\text { Fat trim wt } \\
0 \mathrm{~mm} \text { of fat trim }\end{array}$ & .32 & .09 & .43 & .11 & .17 & .16 \\
\hline $\begin{array}{l}\text { Bone wt } \\
0 \mathrm{~mm} \text { of fat trim }\end{array}$ & .39 & .09 & .46 & .11 & .19 & .16 \\
\hline Carcass lean wt ${ }^{\mathrm{d}}$ & .28 & .08 & .25 & .10 & .39 & .18 \\
\hline Carcass fat $w^{t e}$ & .29 & .09 & .40 & .10 & .15 & .16 \\
\hline Longissimus muscle fat, $\%^{f}$ & .49 & .09 & .36 & .10 & .75 & .20 \\
\hline $9-10-11$ rib fat, $\%^{f}$ & .26 & .08 & .33 & .10 & .13 & .16 \\
\hline Shear force ${ }^{g}$ & .12 & .08 & .05 & .09 & .31 & .17 \\
\hline Tenderness score ${ }^{\mathrm{h}}$ & .22 & .08 & .12 & .09 & .51 & .18 \\
\hline Juiciness score $\mathrm{e}^{\mathrm{i}}$ & .25 & .08 & .06 & .09 & .70 & .20 \\
\hline Flavor score ${ }^{j}$ & .07 & .08 & .08 & .09 & .04 & .15 \\
\hline Muscling score $\mathrm{e}^{\mathrm{k}}$ & .64 & .10 & .64 & .12 & .82 & .20 \\
\hline Fat score ${ }^{k}$ & .27 & .08 & .30 & .10 & .29 & .17 \\
\hline
\end{tabular}

a 4.00 to $4.90=$ slight; 5.00 to $5.90=$ small.

${ }^{b}$ Retail product includes steaks and roasts plus lean trim adjusted to $20 \%$ fat based on chemical analysis of lean trim.

cAll subcutaneous and accessible intermuscular fat removed.

dCarcass lean includes steaks and roasts trimmed to $0 \mathrm{~mm}$ of fat cover plus fat-free lean trim based on chemical analysis of lean trim.

earcass fat includes fat trim plus fat in lean trim based on chemical analysis of lean trim.

Ether-extracted fat.

gShear force required to cut through a $1.27-\mathrm{cm}$ core.

$\mathrm{h}_{4}=$ slightly tough; $5=$ slightly tender; 8 = extremely tender.

$\mathrm{i}_{4}=$ slightly dry; $5=$ slightly juicy; $8=$ extremely juicy.

$\mathrm{j}_{4}=$ slightly bland; $5=$ slightly intense; $8=$ extremely intense.

$\mathrm{k}_{\text {Score of }} 3$ to 27 with 6,15 , and 24 reflecting, respectively, low, average, and high based on range in total population. 


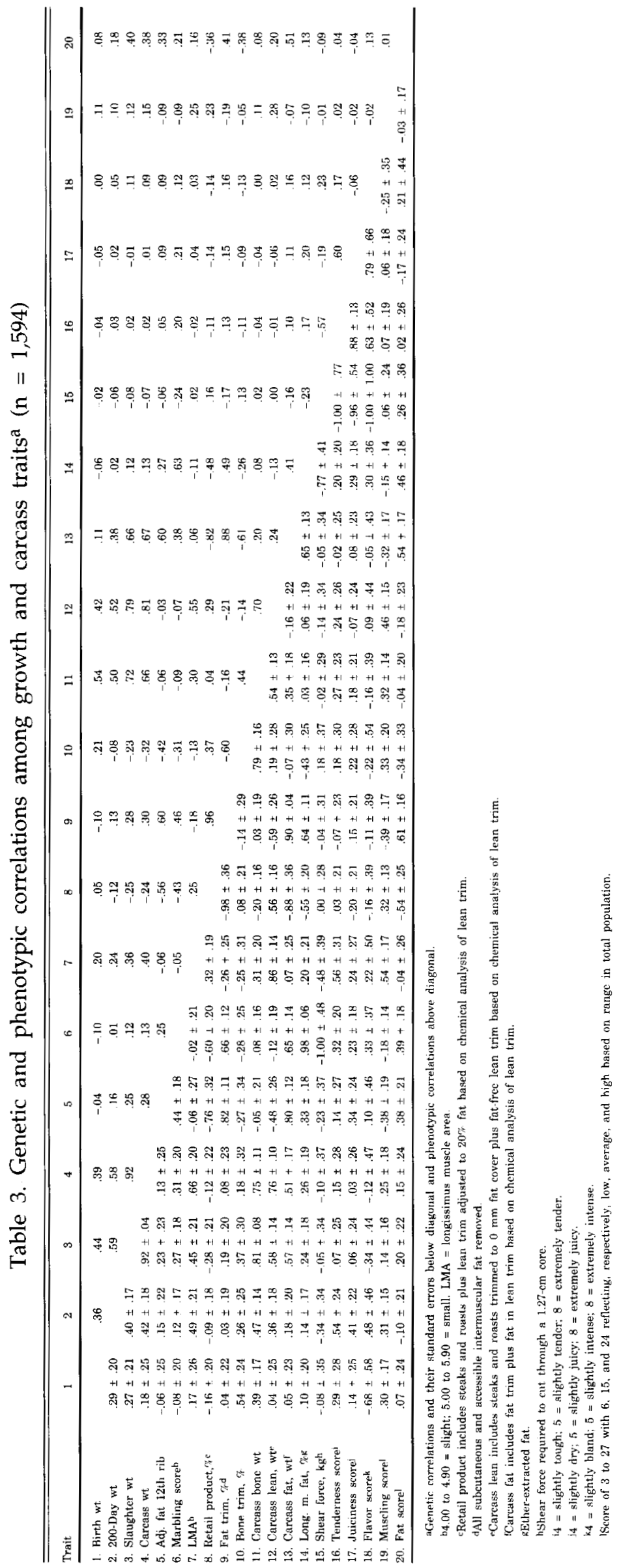


of longissimus muscle fat was high with a low standard error $(.98 \pm .06)$ and was high with shear force but with a high standard error $(-1.00 \pm .48)$. The $r_{g}$ of longissimus muscle area with carcass lean weight was high with a low standard error $(.86 \pm .14)$. The $r_{\mathrm{g}}$ of percentage retail product with percentage fat trim was high $(-.98 \pm .36)$ and the $r_{g}$ of percentage retail product was high with carcass fat weight $(-.88$ \pm .36 ). The $r_{g}$ of percentage fat trim with weight of carcass fat was high with a low standard error $(.90 \pm$ $.04)$. The $r_{g}$ of a subjective muscling score in the live animal with measures of carcass composition were intermediate, suggesting that visual evaluation of differences in thickness of muscle has value in contributing to making changes in carcass composition. The $r_{g}$ of shear force with sensory score for tenderness and juiciness were high but had high standard errors (e.g., $-1.00 \pm .77$ with tenderness and $-.96 \pm .54$ with juiciness).

Phenotypic Correlations. Phenotypic correlations are presented above the diagonal in Table 3 . Phenotypic correlations of marbling score and percentage longissimus muscle fat with palatability attributes were below .30. Even though marbling score is the primary factor determining carcass quality grade in cattle of the age included in this study it does not have high predictive value of end-use properties relating to palatability attributes of individual carcasses from cattle finished on an accelerated program and slaughtered at an average age of $438 \mathrm{~d}$. This is consistent with conclusions of Campion et al. (1975) with cattle of ages and nutritional background similar to those of cattle in this study.

\section{Implications}

Composite populations and contributing purebreds were similar in coefficients of variation for carcass and meat traits. Thus, product consistency is expected to be similar within populations of each. Because genetic variances are similar for composites and contributing purebreds for growth, carcass, and meat traits, selection response is expected to be similar within populations of each. Because of the high genetic correlation between marbling score and other measures of fat in the carcass, simultaneous selection to increase marbling and to increase percentage of retail product is unlikely to be effective.

\section{Literature Cited}

AMSA. 1978. Guidelines for cooking and sensory evaluation of meat. National Live Stock and Meat Board, Chicago, IL.

Boldman, K. G., L. A. Kriese, and L. D. Van Vleck. 1993. A Manual for Use of MTDFREML. A set of programs to obtain estimates of variances and covariances. ARS, USDA, Washington, DC.

Campion, D. R., J. D. Crouse, and M. E. Dikeman. 1975. Predictive value for USDA Quality Grade factors for cooked meat palatability. J. Food Sci. 40:1225.

Cundiff, L. V., D. Chambers, D. F. Stephens, and R. L. Willham. 1964. Genetic analysis of some growth and carcass traits in beef cattle. J. Anim. Sci. 23:1133.

Gregory, K. E., L. V. Cundiff, R. M. Koch, M. E. Dikeman, and M. Koohmaraie. 1994a. Breed effects and retained heterosis for growth, carcass, and meat traits in advanced generations of composite populations of beef cattle. J. Anim. Sci. 72:833.

Gregory, K. E., L. V. Cundiff, R. M. Koch, M. E. Dikeman, and M. Koohmaraie. 1994b. Breed effects, retained heterosis, and estimates of genetic and phenotypic parameters for carcass and meat traits of beef cattle. J. Anim. Sci. 72:1174.

Harvey, W. R., 1985. User's guide for LSMLMW. Mixed Model Least-Squares and Maximum Likelihood Computer Program. The Ohio State University, Columbus (Mimeo).

Koch, R. M., L. V. Cundiff, and K. E. Gregory. 1982. Heritabilities and genetic, environmental and phenotypic correlations of carcass traits in a population of diverse biological types and their implications in selection programs. J. Anim. Sci. 55:1319.

Koots, K. R., J. R. Gibson, C. Smith, and J. W. Wilton. 1994. Analyses of published genetic parameter estimates for beef production traits. 1. Heritability. Anim. Breed. Abstr. 62(5): 309 .

Snedecor, G. W., and W. G. Cochran. 1967. Statistical Methods (6th Ed.). The Iowa State University Press, Ames. 